\title{
LOS TIEMPOS LIBERALES Y SU HISTORIA
}

\author{
Elisa Cárdenas Ayala \\ Universidad de Guadalajara
}

LA VENTANA*

U Ta revista es una ventana. A través de ella una realidad, un paisaje, se vuelven accesibles. Un paisaje limitado, por amplia que sea la ventana. Valorar la producción mexicanista sobre la época que acostumbramos dividir en "República Restaurada" y "Porfiriato" requeriría mucho más que una sola ventana. Comprender el papel historiográfico jugado por cualquier revista demandaría atender a lo sucedido fuera de sus páginas. Ninguno de esos requisitos está satisfecho aquí, sino que la invitación a examinar lo publicado durante 70 años de Historia Mexicana sobre los tiempos liberales se ha procurado honrar leyendo cuidadosamente las páginas de la revista, intentando seguir el diálogo que se produce en ellas y algo del que, rebasándolas, encuentra eco en ellas. Antes que una crítica detallada de los artículos, para la cual, además, no habría espacio, he preferido destacar la que fue su búsqueda; poner de relieve lo

* Agradezco la colaboración de Jorge Omar Mora Rodríguez en la recolección de información indispensable para la redacción de este texto. 
que concentró los esfuerzos de un conjunto representativo de la historiografía mexicanista a lo largo de 70 años. Las lectoras y lectores podrán formarse una idea propia de ese devenir, acercarse con profundidad y criterio propios a cada uno de los textos.

La ventana lleva su marca de fábrica en la firma de Daniel Cosío Villegas; al tratarse del examen de los años liberales, terreno privilegiado de la investigación histórica de su director fundador, la marca se consolida. ${ }^{1}$ Así, imposible ignorar la relación de Historia Mexicana con el Seminario de Historia Moderna cuyos trabajos arrancaron en 1950. La revista, fundada apenas un año después, es en parte un espejo del seminario. Lo expresaba así Luis González a 25 años de publicado el primer número: "Desde el comienzo se especializó la revista en abrirles calle a los artículos relativos a la historia nacional de México y en especial a los conexos con la gran aventura [la Historia moderna]”. ${ }^{2}$ Eso implicó dar a conocer también las lecturas críticas de los productos mayores del seminario conforme tuvo lugar su publicación. Así, a partir de 1954 se publicaron las apreciaciones de grandes lectores sobre los primeros volúmenes de la Historia moderna de México: José Miranda, José Bravo Ugarte, Jorge Iturribaría, Antonio Gómez Robledo. ${ }^{3}$ En 1972 vendrán las lecturas críticas de jóvenes como Lorenzo Meyer y Peter Smith y en 1976 la de Charles Hale sobre la obra completa. ${ }^{4}$

1 Cosío Villegas (coord.), Historia moderna.

2 González, “La pasión del nido” (100), 1976, pp. 530-598, esp. p. 548.

3 Bravo Ugarte, “El Porfirio Díaz de Cosío” (11), 1954, pp. 439-441; “El segundo tomo" (20), 1956, pp. 624-627 y “Catolicismo y porfiriato” (27), 1958, pp. 437-441; J. Miranda, “La República Restaurada” (18), 1955, pp. 253-257; Gómez Robledo, “La república restaurada” (19), 1956, pp. 454460; IturRibaría, “La vida económica” (20), 1956, pp. 628-631; “Aspectos sociales” (28), 1958, pp. 538-541.

4 Hale, "El impulso liberal” (100), 1976, pp. 663-688; L. Meyer, "Sobre Daniel Cosío Villegas” (86), 1972, pp. 234-243; SмIтH, “Sobre Daniel Cosío Villegas” (83), 1972, pp. 538-542. 
Hale destacaba como uno de los objetivos centrales de Cosío Villegas al empeñarse en una obra colectiva de esa magnitud, el romper con la literatura apologética de Porfirio Díaz que hacía del año 1876 una suerte de gran comienzo. Paradójicamente, ahí donde Cosío combatió la idea del origen y el fetichismo de la persona de Díaz, su obra produjo una etiqueta, Porfiriato, que reforzó la división en dos de ese periodo amplio, 1867-1911, acuciosamente estudiado y documentado por él mismo y por su equipo. Más aún, consolidó dos etiquetas: República Restaurada y Porfiriato, que siguen siendo de uso generalizado.

Decía Hale: "la historia moderna, que yo sepa, carece de precedentes como gran obra en colaboración [...] tuvo que ser a uno y el mismo tiempo investigación fundamental y síntesis". ${ }^{5}$ El peso de esta obra única en su tipo, que cambió el paisaje historiográfico mexicano, no podía sino impactar fuertemente en la revista. En esa medida Historia Mexicana se ofrece en parte como una prolongación de la obra coordinada por Cosío. Pero eso, antes que sorprender, obliga a preguntarse por las formas en que esa impronta fue adquiriendo matices a lo largo de 70 años.

UN PAISAJE EN MOVIMIENTO

Sobre los años que corren entre 1867 y 1911, en 70 años de Historia Mexicana se han publicado 179 textos. ${ }^{6}$ De algunos enfoques puede decirse que siempre han estado ahí, cambiando

\footnotetext{
${ }^{5}$ Hale, "El impulso liberal" (100), 1976, p. 678.

${ }^{6}$ El corpus integrado para la elaboración de estas páginas parte de la revisión de los números 1 al 277 de Historia Mexicana y consta de 179 textos entre artículos, reseñas, testimonios, críticas, exámenes de libros, respuestas y obituarios. Para conformarlo se siguieron los siguientes criterios de búsqueda: 1) ingreso de los términos "porfiriato" y "república restaurada" en la base de datos digital del portal en línea www.historiamexicana.colmex.mx; 2) búsqueda manual en la "Guía del número 1 al 150 (1951-1988)" de la revista; 3) revisión del índice número por número para localizar de textos considerados pertinentes al caso; finalmente: 4) examen somero de los textos detectados para
} 
de terreno, ensayando métodos, mudando de perfil teórico: la vida política, la economía, el mundo del trabajo. Otros han ganado gradualmente espacio como expresión de lo que sucede en los estudios mexicanistas dentro y fuera del país. A continuación se presenta el movimiento del paisaje a grandes rasgos siguiendo ejes temáticos y algunas inflexiones interpretativas. Los cuadros que se presentan en el anexo permiten apreciar de manera sintética este panorama dinámico (véase anexo, cuadros 1,3 y 4$)$.

\section{El funcionamiento del sistema}

Los trabajos de Cosío Villegas fundaron en buena medida nuestro conocimiento del sistema político ligado a la Constitución de 1857 y de su despliegue por los gobiernos que suelen identificarse con las etiquetas República Restaurada y Porfiriato. ${ }^{7}$ Del cuadro amplio trazado por François-Xavier Guerra varias décadas más tarde, hay en Historia Mexicana el eco de la reseña de Carlos Arriola. ${ }^{8}$ En esa misma línea, Carlos Martínez Assad dio cuenta de la relación del gobierno federal con las regiones, por medio del caso del sur-sureste. ${ }^{9}$

El ejercicio de la autoridad de Díaz y de su gabinete, en particular el económico, permea en múltiples textos. La figura

confirmar la pertinencia de su inclusión en el corpus, lo cual redujo a 179 la cifra inicial de 221.

7 Además de la Historia moderna, omnipresente en la revista sobre todo en las primeras décadas, pueden verse de Cosío Villegas los artículos: “¡Ya viene la bola!” (6), 1951, pp. 155-183, “¿Dónde está el villano?” (3), 1952, pp. 429-448; "El porfiriato, era de consolidación” (49), 1963, pp. 76-87 y "Enlace y moraleja” (20), 1952, pp. 506-527.

8 Guerra, Le Mexique; Arriola, "Porfiriato y revolución” (141), 1986, pp. 173-194.

9 Martínez Assad, "Del fin del porfiriato a la Revolución” (171), 1994, pp. 487-504. 
emblemática de los jefes políticos es estudiada por Romana Falcón, Brígida von Mentz y, recientemente, Laura Brondino. ${ }^{10}$ En cuanto a los mecanismos de relevo del poder, en 1989 se publicó el trabajo de Héctor Martínez y Francie Chassen sobre elecciones en Oaxaca que puede considerarse precursor en alguna medida de desarrollos historiográficos recientes. ${ }^{11}$

La caracterización de las élites dirigentes ha sido también tema de interés: los influyentes "científicos" son centrales en el artículo en que, en 1971, Dirk Raat se propuso desmontar los lugares comunes sobre el vínculo entre los intelectuales porfiristas y el racismo. ${ }^{12}$ Llama la atención que el texto de tema más que cercano, de la autoría de Moisés González Navarro, en 1988, no haga referencia al texto de Raat, que no pudo desconocer. ${ }^{13}$ Otro estudio sobre élites políticas es el de Almada Bay sobre Obregón y Calles, que enfatiza su pertenencia a redes de parentesco comprensibles en la larga duración y su formación política como regidores porfirianos. ${ }^{14}$

En temas menos comunes, pero igualmente centrales, en 1989 Alicia Hernández planteó un acercamiento al ejército porfiriano, buscando esclarecer su composición, organización y función política, lo mismo que las razones de su derrota en $1911 .{ }^{15}$ En este mismo campo, el seguimiento por Garciadiego de una trayectoria individual al servicio de las armas le permite caracterizar

10 FALcón, "La desaparición de jefes políticos" (147), 1988, pp. 423-467; Von Mentz, "Trabajo minero" (199), 2001, pp. 555-607; BRondino, “De subdelegado a jefe político" (272), 2019, pp. 1463-1538.

${ }_{11}$ Martínez y Chassen, "Elecciones y crisis política” (154), 1989, pp. 523554. Véase Gantús y Salmerón (coords.), Prensa y elecciones, reseñado por FERUllo (262), 2016, pp. 964-968.

12 RaAt, "Los intelectuales” (79), 1971, pp. 412-427.

13 González Navarro, "Las ideas raciales de los científicos, 1890-1910" (148), 1988, pp. 565-583.

14 Almada, "De regidores porfiristas" (238), 2010, pp. 729-789.

15 Hernández Chávez, “Origen y ocaso” (153), 1989, pp. 257-296. 
la política porifiriana en la materia y subrayar el papel de las relaciones personales de fidelidad en la política de la época. ${ }^{16}$

Desde las primeras dos décadas de vida de la revista se exploraron los vínculos entre poder político y poder económico, en particular el ostentado por el capital extranjero con énfasis en sus relaciones con el gobierno de Porfirio Díaz. Se hizo esto partiendo del estudio de "grandes casos": el dominio regional del clan Terrazas y los intereses extranjeros y oligárquicos. El estado de Chihuahua fue el espacio privilegiado de esta exploración. ${ }^{17}$ También se esbozaron amplios panoramas de los problemas sociales mostrando la potencia del enfoque regional. ${ }^{18}$

\section{El mundo rural}

El mundo rural se hizo presente en la revista desde sus inicios, a través de lecturas de la Historia moderna de México. ${ }^{19}$ En 1968, Edith Boorstein Couturier recuperaba la historia de una hacienda hidalguense apoyándose en entrevistas con antiguos trabajadores y en el archivo de la propia hacienda. ${ }^{20}$ También con acceso a fuentes privilegiadas, el estudio de Jan Bazant mostró el funcionamiento de la escuela de una hacienda. ${ }^{21}$ Algunas grandes propiedades norteñas fueron estudiadas en trabajos arriba citados. ${ }^{22}$ El estudio de conflictos por el agua del río $\mathrm{Na}$ zas en la región de La Laguna evidenció el entrecruzamiento de poderes locales, gobierno federal, intereses extranjeros, empresas nacionales y agricultura. ${ }^{23}$ Mientras que la cuestión del agua

\footnotetext{
16 Garciadiego, "Higinio Aguilar" (163), 1992, pp. 437-488.

17 Sims, "Espejo de caciques" (71), 1969, pp. 379-399; Wasserman, "Oligarquía” (87), 1973, pp. 279-319.

18 SANDELs, “Antecedentes de la revolución” (95), 1975, pp. 390-402.

19 Iturribaría, “Aspectos sociales” (28), 1958, pp. 538-541.

20 Boorstein Couturier, “Modernización y tradición” (69), 1968, pp. 35-55.

21 J. BAZAnT, “La escuela primaria” (113), 1979, pp. 163-179.

22 Véase la nota 18.

23 Kroeber, “La cuestión del Nazas” (79), 1971, pp. 428-456.
} 
y la producción agrícola volverá apenas en 2015, en un trabajo sobre Aguascalientes, otros textos explorarán los vínculos entre la producción agrícola especializada y la hacienda pública llamando la atención del lector sobre las regiones henequeneras y cafetaleras del país. ${ }^{24}$

Grandes temas del mundo rural, como la estructura de la propiedad y las condiciones de vida de sus habitantes, acompañan la discusión de una obra fundamental, las Estadísticas sociales y las Estadísticas económicas del porfiriato, objeto de propuestas de rectificación por parte de varios historiadores. Dentro de la revista, John H. Coatsworth desde 1976 y Jean Meyer en 1986.25 Ese debate en torno a cifras y fuentes confiables para reconstruir la historia del periodo, y a interpretaciones divergentes, tuvo por centro la figura y la energía de Moisés González Navarro discutiendo, primero con Meyer sobre las categorías y criterios de conformación de las Estadísticas, y luego con Katz sobre las categorías, para comprender el trabajo rural (esclavitud, peonaje, servidumbre) y las fuentes que permiten su exploración. ${ }^{26}$

El tratamiento de las relaciones entre el mundo rural, campesino e indígena y el Estado liberal, haya sido éste juarista, lerdista, porfirista o gonzalista, evidencia un punto de inflexión en un artículo de Romana Falcón, publicado en 2005, centrado en las respuestas del Estado liberal ante las rebeliones campesinas e

\footnotetext{
${ }^{24}$ Gómez Serrano, “"Remansos de ensueño”” (255), 2015, pp. 1001-1097; Zuleta, "Hacienda pública” (213), 2004, pp. 177-247; Rodríguez Centeno, "Fiscalidad y café" (213), 2004, pp. 93-128.

25 González Navarro, Estadísticas sociales; Seminario de Historia MoDERna De México, Estadísticas económicas; CoATsworth, "Anotaciones sobre la producción de alimentos" (102), 1976, pp. 167-187; J. MEYER, "Haciendas y ranchos” (139), 1986, pp. 477-509. Meyer se hace eco de Guerra, Le Mexique, un libro cuya reseña presenta ese mismo año Arriola, "Porfiriato y Revolución” (141), 1986, pp. 173-194.

26 GonzÁlez Navarro, "Falacias, calumnias" (142), 1986, y “Kaerger” (143), 1987, pp. 527-551. Sobre la obra de Kaerger, la reseña de Spenser y Melville, “Sobre Karl Kaerger" (143), 1987, pp. 579-581.
} 
indígenas. Este texto combate la interpretación de una marcada discontinuidad entre los gobiernos de la República Restaurada y los años porfiristas; la considera producto del empeño por preservar la imagen de la República Restaurada como una época inmaculada. Lo hace atendiendo al recurso a la violencia armada como respuesta privilegiada del Estado frente a las rebeliones campesinas. El análisis enfatiza -en la línea reflexiva de Bonfil Batalla- la forma en que la negación del indio y del campesino se sitúa en el corazón de la identidad mexicana. ${ }^{27}$

En este ámbito de interés por las resistencias y los recursos políticos de los de abajo, se inscriben la reconstrucción de una revuelta popular en Misantla, Veracruz, realizada por Renée González de la Lama en 1989, el trabajo de José Alfredo Rangel Silva sobre las estrategias de las comunidades potosinas en defensa de sus tierras, lo mismo que el reciente de Falcón que explora la presencia de agravios de larga data en el estallido de reivindicaciones revolucionarias. ${ }^{28}$ En 2017, Nicolás Cárdenas García, interesado en el periodo revolucionario, mostró el trato de que fue objeto el pueblo yaqui bajo los gobiernos liberales hasta su casi exterminio. ${ }^{29}$

En las antípodas del ideal liberal estuvieron los pueblos nómadas, que escapaban al control del gobierno. Varios autores muestran que el Estado liberal no domina por entonces enteramente el territorio, entre otros Amparo Angélica Reyes Gutiérrez, Ignacio Almada Bay y David Contreras Tánori quienes exploran la autodefensa de los vecinos sonorenses frente a las incursiones apaches..$^{30}$ No sólo no lo domina, sino que no tiene a

\footnotetext{
${ }^{27}$ FALcón, “El Estado liberal” (216), 2005, pp. 973-1048.

28 González de la Lama, "Los papeles de Díaz Manfort” (154), 1989, pp. 475-521; Rangel, "Los comuneros” (255), 2015, pp. 937-1000; Falcón, “Las corrientes subterráneas" (277), 2020, pp. 7-60.

29 Cárdenas García, “Lo que queremos” (264), 2017, pp. 1863-1921.

30 Reyes, Almada y Contreras, "Medidas ofensivas" (259), 2016, pp. 1193 1269.
} 
su disposición su representación científica completa, como mostró Bernardo García Martínez al estudiar los primeros esfuerzos para dotar al país de una cartografía rigurosa. ${ }^{31}$ La ciencia y las comunidades científicas del periodo volverán a las páginas de la revista varias décadas después, con textos como el de Guillermo Palacios sobre el saqueo arqueológico o, más recientemente, el de David Pretel sobre la frontera forestal yucateca. ${ }^{32}$

Sobre el vasto tema de la propiedad comunal y las políticas liberales, el dossier coordinado en 2017 por Emilio Kourí invita a examinar desde una óptica revisionista la relación de los pueblos con los procesos de desamortización y privatización, al considerarlos agentes no unánimes dentro de esos mismos procesos. Los textos que conforman este dossier, de Helga Baitenmann, Édgar Mendoza y Fernando Pérez Montesinos exploran el tema desde varios ángulos que contribuyen a ese objetivo. ${ }^{33}$

\section{Educación}

Por encima de diferencias ideológicas, por varias generaciones las élites atribuyeron a la instrucción un carácter redentor de los vicios, moralizador e integrador de la nación; las discrepancias afloraron cuando se trató de precisar el perfil deseado para la nación. Bajo el dominio liberal, el mayor objetivo fue arrancar la educación de manos del clero, como lo muestra el texto que siembra estos temas en la revista, de Josefina Zoraida Vázquez. ${ }^{34}$

\footnotetext{
31 García Martínez, “La Comisión Geográfica Exploradora” (96), 1975, pp. 485-555.

32 Palacios, "El cónsul Thompson" (257), 2015, pp. 167-288; Pretel, "Reacciones en cadena” (277), 2020, pp. 259-311.

33 Kourí, "Sobre la propiedad comunal de los pueblos" (264), 2017, pp. 1923 1960; Baitenmann, “Ejerciendo la justicia” (264), 2017, pp. 2013-2072; MenDOZA, “Tierras de común repartimiento” (264), 2017, pp. 1961-2011; PéreZ Montesinos, "Geografía, política y economía” (264), 2017, pp. 2073-2149.

34 VÁzQuez, "La república restaurada y la educación” (66), 1967, pp. 200-211.
} 
A lo largo de varios años es posible seguir, en las páginas de Historia Mexicana, gracias a diversos autores, los esfuerzos en pro de un sistema educativo, desde la construcción institucional en materia de enseñanza básica, en particular en el Distrito Federal, hasta la educación especializada ligada a prácticas profesionales prioritarias para el régimen..$^{35}$ La enseñanza particular sólo está representada por el caso de la escuela de una hacienda. ${ }^{36}$

Recientemente, Édgar Iván Espinosa Martínez, interesado en instrumentos y métodos, estudió los catecismos cívicos, adaptación secularizada de instrumentos novohispanos de cristianización, “artefactos literarios” para apoyar la construcción ciudadana. ${ }^{37} \mathrm{El}$ autor enfatizó la centralidad de la infancia, concepto cuya versión mexicana se forja a finales del xIX. En la revista sólo otros dos autores se centran en el tema de la niñez para el periodo que nos retiene: Alberto del Castillo Troncoso, quien analizó las representaciones de la niñez a partir de fuentes visuales, y Fabio Kolar, cuyo estudio del texto autobiográfico de Andrés Iduarte se publicó en 2016. ${ }^{38}$

\section{Relaciones internacionales, economía y migración}

En 1985, en el marco de un análisis crítico de los estudios históricos sobre migración, Clara E. Lida constataba el largo predominio de las temáticas de relaciones diplomáticas y comerciales en los estudios sobre relaciones internacionales. ${ }^{39} \mathrm{Las}$ páginas de Historia Mexicana lo confirman: igual que sucede

35 DÍAz, "La escuela nacional primaria” (113), 1979, pp. 59-90; MARTínEz JiménEz, “La educación elemental” (136), 1973, pp. 514-552; M. BAZANT, “La enseñanza y la práctica” (131), 1984, pp. 254-297.

36 J. BAZANT, “La escuela primaria de la hacienda” (113), 1979, pp. 163-179.

37 Espinosa Martínez, “Educación y ciudadanía” (256), 2015, pp. 1541-1581.

38 Castillo Troncoso, "Entre la criminalidad y el orden cívico" (190), 1999, pp. 277-320; Kolar, “Memorias en acción” (261), 2016, pp. 299-357.

39 LIDA, “Inmigrantes españoles” (138), 1985, pp. 219-239, y “España y México: relaciones diplomáticas” (192), 1999, pp. 719-730. 
con otros campos, éste toma pie en la Historia moderna de México con la reseña de Carlos Bosch García al 5 volumen, publicada en $1961 .{ }^{40}$ Vienen enseguida textos centrados también en cuestiones diplomáticas: en 1966, una reseña de Harry Bernstein daba cuenta de la publicación de un importante catálogo ${ }^{41}$ y al año siguiente el comentario de Iso Brante Schweide sobre un libro de Friedrich Katz motivaba la respuesta de un Katz desconcertado (el término es suyo) por una reseña que a su juicio evadía el contenido central de su obra sobre la diplomacia alemana en México y en cambio proporcionaba de ella una imagen distorsionada. ${ }^{42}$ En 1968 José Rojas Garcidueñas analizó la trayectoria diplomática de Salado Álvarez, transcurrida entre los años porfirianos y la Revolución. ${ }^{43}$ Aunque parecen privilegiar otros espacios de publicación, los estudios sobre cuestiones diplomáticas siguen siendo un campo activo, como muestra el texto de Itzel Toledo García y Silvestre Villegas Revueltas sobre las relaciones de nuestro país con Bélgica, publicado en 2017. ${ }^{44}$

Investigaciones realizadas en perspectiva económica, política y social pusieron de relieve aspectos de la política internacional mexicana en materia de inversiones y negocios internacionales, de recursos naturales y de su entrelazamiento con el poder político, en particular los trabajos sobre las regiones fronterizas con Estados Unidos, como algunos ya referidos. En 1982, Cathryn Thorup analizó la condición del país como terreno de

\footnotetext{
40 Bosch García, “Diplomacia porfiriana” (39), 1961, pp. 497-501.

41 Bernstein, "Sobre Guadalupe Monroy” (61), 1966, pp. 86-88.

42 Brante Schweide, “Tres libros alemanes” (62), 1966, pp. 300-306; Katz, "Friedrich Katz responde". Brante Schweide presenta en su examen de libros tres obras; sólo interesa en estas páginas la referida de Katz, puesto que las otras dos quedan fuera de la temática general aquí considerada. Se trata de la obra de Katz Deutschland, Díaz, de la cual, por cierto, aún no existe traducción al español.

43 Rojas Garcidueñas, “Don Victoriano Salado Álvarez” (68), 1968, pp. 569-586.

44 Toledo y Villegas, “La reanudación” (266), 2017, pp. 605-658.
} 
enfrentamiento de intereses extranjeros rivales, contribuyendo a la comprensión de la tensión histórica entre inversión extranjera y dependencia comercial. Thorup argumentó, contra lo comúnmente reiterado, que un apoyo deliberado a los intereses británicos desde instancias del gobierno sólo se documenta al llegar José Yves Limantour al Ministerio de Hacienda en 1892, como portavoz de un grupo que desconfiaba de Estados Unidos. ${ }^{45}$ Temas relacionados con la inversión británica serían analizados posteriormente por Reinhard Liehr y Mariano Torres Bautista. ${ }^{46}$ En otro tenor, Sandra Kuntz revisó una historia emblemática del desarrollo porfiriano, la del ferrocarril, al enfatizar la función que cumplió para el mercado interno este medio de transporte tantas veces visto únicamente en función de su representatividad de los capitales extranjeros. ${ }^{47}$

Las relaciones con el mundo anglosajón, tanto con Estados Unidos como con la Gran Bretaña, son claves para comprender no únicamente el desarrollo económico, sino la diversificación de cultos religiosos; así la propagación del metodismo siguió en buena medida el trazo de las vías férreas y la implantación de las compañías mineras inglesas. ${ }^{48}$ Los vínculos internacionales también muestran la genealogía de los deportes y diversiones practicados por las élites. ${ }^{49}$

En 1999 un texto de Agustín Sánchez Andrés reabrió la publicación de un conjunto de estudios de relaciones internacionales. ${ }^{50}$ Propiciados por el centenario de la guerra del 98,

45 Thorup, “La competencia económica” (124), 1982, pp. 599-641. El testimonio político de Limantour había sido analizado por Jorge ITURRIBARÍA, “La versión de Limantour” (63), 1967, pp. 382-418.

46 Liehr y Torres, "Las free-standing companies británicas” (187), 1998, pp. 605-652.

47 Kuntz, "Mercado interno” (177), 1995, pp. 39-66.

48 Bastian, “Metodismo” (129), 1983, pp. 39-71.

49 Beezley, “El estilo porfiriano” (130), 1983, pp. 265-284.

50 SÁnCHEz Andrés, “La normalización de las relaciones” (192), 1999, pp. 731-766. 
estos trabajos tienen en común denominador el interés por las relaciones hispanomexicanas. Una parte de ellos se interesa en temáticas de negocios y financieras y muestra el peso de estas cuestiones sobre las relaciones diplomáticas y avances sobre historia de la banca, así como, a escala regional, la incidencia de los intereses particulares en la política y las dinámicas de implantación y desarrollo empresarial en el mundo agrícola. ${ }^{51}$ En este ámbito, desde una óptica regional, en 1990, con apoyo en fuentes bancarias que muestran la intervención de una consultora internacional, Gladys Lizama había reconstruido el proceso de formación de capitales en el Bajío zamorano en la primera década del siglo xx. ${ }^{52}$

El tema de las relaciones hispanomexicanas de fin del siglo XIX está atravesado por la compleja cuestión de la lucha independentista cubana (aunque ésta es visible sólo indirectamente en las páginas de la revista) y por la evidencia del Caribe como teatro de rivalidades imperiales, entre un poderío español en sus últimos respiros y el expansionismo estadounidense en pleno crecimiento, ante los cuales, como escribió Rafael Rojas, “Toda América Latina estaba implícitamente involucrada en el conflicto, más que como espectador, como un actor indirecto". ${ }^{53}$ En esas aguas México, aunque acotado por las circunstancias, buscó una política con personalidad propia, al tiempo que era escenario de creciente interés para inversores, nacionalistas, disidentes, independentistas y servicios secretos. ${ }^{54}$ Fuegos cruzados de batallas que parecen ajenas pero que no sólo la geopolítica y la

51 LidA, “España y México: relaciones diplomáticas” (192), 1999, pp. 719730; Marichal, "De la banca privada" (192), 1999, pp. 767-793; GAmbOA, "Manuel Rivero Collada" (192), 1999, pp. 795-823; CerutTi, "Propietarios y empresarios" (192), 1999, pp. 825-870.

52 Lizama, "Los capitales zamoranos" (156), 1990, pp. 1029-1061.

53 Rojas, "Retóricas de la raza" (196), 2000, pp. 593-629, esp. p. 593. De él mismo, "La política mexicana” (180), 1996, pp. 783-805.

54 Además de los artículos ya citados sobre estos temas, véase Granados, "Las juntas patrióticas" (195), 2000, pp. 379-429. 
coyuntura hacen propias; también los intelectuales y la opinión pública dieron rostros mexicanos (en indispensable plural) a los grandes debates de fin de siglo, como años atrás había sucedido con la aclimatación del positivismo de la mano de Gabino Barreda. ${ }^{55}$

Del llamado que hacía Clara E. Lida en 1985, a una historia enfocada en los sujetos migrantes, se encuentra en la revista un eco 30 años después en las páginas dedicadas a los procesos de naturalización por Pablo Yankelevich, quien hace un lugar importante a la normatividad y políticas de los gobiernos liberales en materia de extranjería antes de efectuar el ejercicio central del texto, de carácter cuantitativo. ${ }^{56}$

En su reflexión, Lida subrayaba, entre los obstáculos a enfrentar por los estudiosos sobre migración en México, la prevalencia de filias y fobias que, siendo identificables en los actores históricos, permean entre los historiadores. Su texto forma parte de un conjunto que permite profundizar en la comprensión de las lógicas que presidieron, en aquellos años, la construcción de una "mexicanidad", por la vía de subrayar factores de inclusión, pero sobre todo de exclusión: quiénes eran bienvenidos al universo ideal de lo mexicano y quiénes, en cambio, estorbaban ese ideal.

\section{El mundo obrero}

En general la historia obrera ha sido estudiada con interés en su politización y organización, con énfasis en las movilizaciones reivindicativas, los obreros vistos como fuerza de cambio social. Los primeros trabajos publicados sobre el universo del trabajo se interesaron en episodios emblemáticos de la lucha obrera y

55 VÁzquez, "La República Restaurada y la educación” (66), 1967, pp. 200-211.

56 Yankelevich, “Mexicanos por naturalización” (256), 2015, pp. 1729-1805. 
enfatizaron los vínculos de ésta con la disidencia política de fines del régimen de Díaz: Moisés González Navarro escribió sobre huelgas en 1956 y más tarde reconstruyó la historia del salario mínimo; Rodney Anderson reflexionó sobre la crisis laboral de 1906 y la forma en que fue encarada por el gobierno. ${ }^{57}$ Los principales protagonistas de esta historia son los obreros textiles y los mineros.

El mundo del trabajo en los centros mineros y sus vínculos con el entorno inmediato fueron caracterizados por Brígida von Mentz, quien mostró los contrastes entre las prácticas de la minería tradicional y las del naciente proletariado industrial; las condiciones de vida ligadas a ambas, además de los mecanismos de control a escala local de la protesta laboral y política..$^{58}$ En la movilización de los mineros fue importante la penetración de los clubes liberales y del anarquismo, un tipo de oposición insoportable para el régimen, como ilustra la reconstrucción hecha por Ward S. Albro III de un episodio de represión política. ${ }^{59}$ La movilización obrera se propició también desde horizontes ideológicos opuestos a la laicización y al concepto de lucha de clases, como puede verse en los textos de Manuel Ceballos y de Jean-Pierre Bastian. ${ }^{60}$

\section{Política y religión}

A mediados de los años ochenta se puso de manifiesto la renovación de la historia de las relaciones entre política y religión,

\footnotetext{
57 Además reseñó publicaciones sobre temas laborales. GonzÁlez NAVArro, “Las huelgas textiles” (22), 1956, pp. 201-216; “El primer salario” (111), 1979, pp. 370-400, y “Educación y trabajo” (24), 1957, pp. 620-625; ANDERson, “Díaz y la crisis laboral” (76), 1970, pp. 513-535.

58 Von Mentz, “Trabajo minero” (199), 2001, pp. 555-607.

59 Albro III, “El secuestro de Manuel Sarabia” (71), 1969, pp. 400-407.

60 Bastian, “Metodismo” (129), 1983, pp. 39-71; Ceballos Ramírez, “La encíclica” (129), 1983, pp. 3-38.
} 
desde perspectivas que buscaron desprenderse de los estereotipos que por décadas habían dominado ese campo. Los trabajos de Ceballos Ramírez contribuyeron a romper la identidad entre catolicismo y conservadurismo, y los de Bastian a mostrar la diversificación del cristianismo acaecida en la época y sus vínculos con la oposición política. ${ }^{61}$ Ambos textos constituían un adelanto de investigaciones más amplias que serán reseñadas en la propia revista. ${ }^{62} \mathrm{~A}$ varios años de distancia, la crítica de Franco Savarino subraya límites de estas obras, preconiza y pone a prueba herramientas de otras disciplinas para el estudio histórico de los fenómenos religiosos. ${ }^{63}$ Sin cuestionar lo fructífero de un abordaje de este tipo, insisto en el carácter renovador de estas obras que en su momento abrieron brecha en un campo severamente estereotipado.

El vasto tema del lugar social y político de las religiones comprende en Historia Mexicana desde perspectivas biográficas, como la desarrollada por José Miguel Romero de Solís sobre el insólito caso del rompimiento de un obispo mexicano con las autoridades romanas, hasta estudios comparativos, como el de Manuel Suárez Cortina sobre España y México. ${ }^{64}$ La vitalidad de este campo la atestiguan el texto de Guillermo Zermeño sobre el retorno de los jesuitas, así como los recientes artículos de David Carbajal sobre el liberalismo del padre Agustín Rivera y de Héctor Strobel sobre los religiosos exclaustrados. ${ }^{65}$

61 Bastian, "Metodismo” (129), 1983, pp. 39-71 y "Las sociedades protestantes y la oposición a Porfirio Díaz, 1877-1911” (147), 1988, pp. 469-512; Ceballos Ramírez, “La encíclica” (129), 1983, pp. 3-38.

62 Baldwin, "Sobre Jean-Pierre Bastian” (158), 1976, pp. 363-365; Bastian, "Sobre Manuel Ceballos Ramírez" (169), 1993, pp. 166-168.

63 Savarino, "Religión y sociedad” (183), 1997, pp. 617-651.

64 Romero de Solís, “Apostasía” (146), 1987, pp. 239-282; SuÁrez Cortina, “Religión” (265), 2017, pp. 341-400.

65 Zermeño, “El retorno de los jesuitas” (256), 2015, pp. 1463-1540; CARBAJAL, “Agustín Rivera” (276), 2020, pp. 1549-1596; STROBEL, “Itinerario” (275), 2020, pp. 1143-1187. 
La prensa

Para pocos periodos juega la prensa un papel tan crucial en la reconstrucción histórica como para los tiempos liberales. Una de las razones centrales es su calidad de actor-durante mucho tiempo soslayada-, aunada a su condición de fuente. Para los años que van de 1967 a 2011, en las páginas de Historia Mexicana la discusión sobre el tema de la prensa es recurrente desde diversas ópticas. Ya en 1955, en su reseña de la Historia moderna de México, José Miranda refutaba las críticas formuladas a la obra por su recurso a la prensa liberal como fuente privilegiada. ${ }^{66}$

Como objeto de estudio, la prensa figuró por primera vez en 1989 en las páginas de Claude Dumas sobre la clerical conservadora. ${ }^{67}$ Casi una década más tarde, vieron la luz el texto de Judith de la Torre Rendón sobre prensa gráfica y el de Julieta Ortiz Gaitán sobre arte, publicidad y consumo en la prensa, ambos elaborados desde un enfoque de historia cultural..$^{68} \mathrm{En}$ 2009 se publicó el estudio de Arno Burkholder sobre el periódico Excelsior, que dedica un espacio a la caracterización de la prensa mexicana anterior al estallido revolucionario. ${ }^{69}$ Antes, se había dado a conocer el artículo de Elías Palti que enfatiza los vínculos entre prensa, política y esfera pública, y la politización de los espacios de espectáculo -algo señalado antes por Susan E. Bryan- mediante un estudio de caso. ${ }^{70}$

La libertad de prensa, tema en el que se aquilata el difícil equilibrio entre el liberalismo como ideología y como práctica

${ }^{66}$ J. Miranda, “La República Restaurada” (18), 1955, pp. 253-257.

67 Dumas, "El discurso de oposición" (153), 1989, pp. 243-256.

${ }^{68}$ De la Torre, "Las imágenes fotográficas" (190), 1998, pp. 343-373; OrTiz, “Arte, publicidad y consumo" (190), 1998, pp. 411-435.

${ }^{69}$ Burkholder, "El periódico que llegó a la vida nacional” (232), 2009, pp. 1369-1418.

70 Palti, “La Sociedad Filarmónica” (208), 2003, pp. 941-978; Bryan, “Teatro popular” (129), 1983, pp. 130-169. 
política desde los tiempos gaditanos, es objeto de una exploración más tardía. Hubo que esperar hasta 2015 para encontrar un texto de Laurence Coudart sobre su regulación. ${ }^{71}$ El segundo de esta autora vendrá en 2019, en el marco del dossier coordinado por Fausta Gantús, cuyo examen del papel jugado por la sátira visual, primero sobre la figura específica de Porfirio Díaz, luego de manera más amplia como expresión política insumisa, contribuye a la comprensión del ejercicio de la libertad de prensa desde el periodismo. ${ }^{72}$

\section{La vida urbana}

El estudio de la vida urbana durante los tiempos liberales es un campo que acusa la centralización de recursos humanos y fuentes en la ciudad de México. Deben destacarse los estudios sobre la policía, primero el de Pedro Santoni y, recientemente, el de Diego Pulido Esteva; sobre la impartición de justicia, el de Elisa Speckman; sobre salud, el de Lourdes Márquez Morfín. ${ }^{73}$ Los trabajos publicados sobre diversos aspectos de la vida de la ciudad, como el de Mario Barbosa sobre los empleados públicos, el de Cristina Sánchez Parra sobre la publicidad de las casas comerciales, la reflexión sobre las representaciones populares de la vida urbana a cargo de Tomás Cornejo, y el estudio de Campos sobre la incorporación de Cuauhtémoc como héroe a la pedagogía urbana de la nación, posibles gracias a la

71 Coudart, “La regulación” (258), 2015, pp. 629-687.

72 Coudart, "La libertad de imprenta” (273), 2019, pp. 205-256; Gantús, “¿Héroe o villano?” (261), 2016, pp. 209-256 y “Amagada, perseguida y ¿sometida?” (273), 2019, pp. 257-310.

73 Santoni, "La policía de la ciudad de México" (129), 1983, pp. 97-129; PuliDo, “Trabajo, clase y prácticas policiales" (270), 2018, pp. 667-712; SPECKMAN, “Los jueces” (220), 2006, pp. 1411-1466; Márquez Morfín, “La sífilis” (255), 2015, pp. 1099-1161. 
disponibilidad de archivos, sugieren una infinidad de temáticas aún por explorarse. ${ }^{74}$

La historia de la vida urbana abre posibilidades a estudios que pueden considerarse de frontera, donde la historia es obligadamente interdisciplinaria. Ya se situaba ahí en 1967 el espléndido texto de Jorge Manrique, explorador de la modernidad y el nacionalismo desde el terreno artístico. ${ }^{75}$ También el citado de Susan Bryan, quien considera al teatro popular como observatorio de las transformaciones y conflictos sociales, y con toda claridad debe considerarse tal la discusión dada por el musicólogo Ricardo Miranda a propósito de un libro de historia cultural. ${ }^{76}$

Mirar la ciudad abrió la ventana a la historia de las mujeres y luego a la perspectiva de género. No es éste uno de los fuertes de la revista, pero tiene algunos antecedentes, desde la historia social y cultural, en artículos como el de Lillian Briseño, que explora mecanismos de transmisión de valores en una sociedad donde la oralidad es dominante y muestra la comunidad de referencias morales entre liberales y conservadores. ${ }^{77}$

El primer texto que incorpora una perspectiva de género rastrea a las mujeres de la época por medio de expedientes criminales, evidenciando en la transgresión una ventana para el estudio de las clases populares. ${ }^{78}$ Vendrá luego el artículo de Silvia Arrom sobre las Señoras de la Caridad, que dota a la acción social y política confesional de un rostro femenino intensamente

\footnotetext{
74 Barbosa, “Capacitación y posición social” (270), 2018, pp. 747-783; Sánchez Parra, "La publicidad” (276), 2020, pp. 1597-1646; Cornejo, "Representaciones populares" (260), 2016, pp. 1601-1651; CAmpos, "Cuauhtémoc" (264), 2017, pp. 1819-1861.

75 Manrique, “Arte, modernidad” (66), 1967, pp. 240-252.

${ }^{76}$ Bryan, "Teatro popular" (129), 1983, pp. 130-169; R. Miranda, "Musicología e historia cultural” (261), 2016, pp. 359-401.

77 Briseño Senosiain, “La moral en acción” (218), 2005, pp. 419-460.

78 Speckman, "Las flores del mal” (185), 2017, pp. 183-229.
} 
activo. ${ }^{79}$ Después, la perspectiva de género persiste en la lista de pendientes.

\section{Discusiones historiográficas}

Los materiales publicados, en tanto avances de investigaciones específicas, constituyen movimientos dentro de un paisaje historiográfico cambiante. Producen saber sobre alguna temática precisando datos, acudiendo a fuentes antes no utilizadas o revisando su interpretación. Algunos reservan un espacio importante para la discusión de lo previamente escrito en la materia; pocos se asignan específicamente ese objetivo como central: al texto de Martín Quirarte publicado en 1956 sobre historia política, le sigue el de Clara E. Lida en 1985, sobre migración española en México, después el de Aurora Gómez-Galvarriato, centrado en la historiografía de la industrialización, en 2003. ${ }^{80}$ Otros escritos que podemos considerar específicamente historiográficos, además de las reseñas, constituyen revisiones de una trayectoria individual, como el de Álvaro Matute sobre Moisés González Navarro, o el que dediqué a la revisión de la etiqueta porfiriato. ${ }^{81}$

Con este mismo carácter de discusiones historiográficas considero indispensable distinguir tres reflexiones sobre el tema del liberalismo que se extienden sobre el conjunto del periodo: la hecha por Charles Hale, que lo considera una perspectiva historiográfica; la de Laurence Ballard Perry, quien contrasta al modelo liberal con la práctica política; la de Alan Knight,

\footnotetext{
79 Arrom, "Las Señoras de la Caridad" (226), 2007, pp. 445-490.

80 Quirarte, "Historia política” (58-59), 1965-1966, pp. 408-424; Lida, "Inmigrantes españoles” (138), 1985, pp. 219-239; Gómez Galvarriato, “Industrialización” (207), 2003, pp. 773-804.

${ }^{81}$ Matute, "Moisés González Navarro" (257), 2015, pp. 505-511; CÁRdenas Ayala, "El porfiriato" (259), 2016, pp. 1405-1433.
} 
quien considera que la pluralidad de liberalismos constituye una corriente que domina la política mexicana en el largo plazo. ${ }^{82}$

Esta tesis de Knight sobre la continuidad del liberalismo entre los tiempos de la Reforma y los de la Revolución (un binomio cuya discusión está en parte pendiente), con un eje interpretativo que obliga a repensar la cronología de la historia de México, no alcanzó mucho eco en las páginas de la revista dedicadas a la época aquí considerada. Su discusión, a la luz de los textos del corpus utilizado, tendría que tomar en cuenta el tema de la constitucionalidad, factor principal de continuidad entre República Restaurada y Porfiriato, según destaca Hale en su lectura de Cosío Villegas, lo mismo que cuestiones de política práctica en tensión con principios liberales teóricos, como la libertad de prensa o la igualdad entre los ciudadanos, pero tendría que extenderse a la revisión precisamente de lo escrito sobre la Revolución, que forma el punto de llegada de la tríada liberal propuesta por Knight, tema que excede el propósito de estas páginas.

\section{EPÍLOGO}

La historia de los tiempos liberales que se lee en las páginas de Historia Mexicana, en 70 años se desprendió de la marca de Cosío Villegas para asumir la marca de la casa, en un continuo matizar el legado de la Historia moderna de México. Cumplió con creces la ruptura con la lectura apologética de Díaz, además de que profundizó en el estudio de la época por sí misma, aun cuando la Revolución no haya perdido por completo su carácter de vara de medir su propio pasado.

Es una historia apegada a la revisión acuciosa de fuentes, sobre todo escritas, de todo tipo de archivos, y poco afecta a la

82 Hale, “El impulso liberal” (100), 1976, pp. 663-688; Ballard Perry, “El modelo liberal" (92), 1974, pp. 646-699; KNIGHT, "El liberalismo mexicano" (137), 1985, pp. 59-91. 
discusión teórica. Se ha escrito principalmente desde las instituciones del centro de México (expresando una realidad demográfica, educativa y profesional del país) y desde instituciones extranjeras, mayormente estadounidenses y europeas, aunque recibe aportaciones desde otras regiones del país entre las cuales, por cierto, la ciudad de México como región historiográfica empezó a perfilarse en años recientes, evidenciando que la historia nacional que desde ella solía darse por escrita no reemplaza a la historia propia de la ciudad (véase anexo, cuadro 2).

Es una historia que ha transitado de las cifras a los rostros -sin abandonar los números-, de los paisajes generales a los casos particulares, del universo en clave masculina a una sociedad en donde las mujeres se perfilan sin ser sistemáticamente visibles, incluso en los procesos de escritura que, aunque ha sido desproporcionadamente realizada por hombres, cada vez integra a más historiadoras (véase anexo, cuadro 5).

Su exploración rebasa los límites cronológicos de este ensayo, pues diversos autores la enlazan con épocas precedentes y también con los años que le sucedieron, según las temáticas, las fuentes, las preguntas y prioridades de investigación. No conoce límites rígidos.

El diálogo con lo que se lee fuera de la revista, visible sobre todo en las notas a pie de página y en los listados bibliográficos que cierran los artículos, permite también tomar el pulso de la historiografía mexicanista a través del caso de los años liberales. En esa medida Historia Mexicana constituye una ventana sólida, sin duda portadora del sello de la casa desde donde se perfila, abierta a la interacción con el mundo que la hace posible y le confiere sentido: el de la práctica historiográfica. Cabe esperar que enfoques que se ensayan aún con timidez en el estudio de estos años ganen espacio también en las páginas de la revista. Historia Mexicana se ofrece como un espacio dinámico que, respecto a los tiempos liberales, da cuenta de los relevos generacionales, de la complejidad de la gestión de un legado 
historiográfico potente, de la pluralidad y límites de una escritura que remite a un periodo distante con fuertes ecos en el debate público contemporáneo.

\section{REFERENCIAS}

Cosío Villegas, Daniel (coord.), Historia moderna de México, 10 tomos, México, Buenos Aires, Hermes, 1984.

González Navarro, Moisés, Estadísticas sociales del Porfiriato, 1877-1910, México, Secretaría de Economía, Dirección General de Estadística, 1956.

Guerra, François-Xavier, Le Mexique, de l'Ancien Régime à la Révolution, París, L'Harmattan, 1985.

Katz, Friedrich, Deutschland, Díaz und die mexikanische Revolution. Die deutsche Politik in Mexiko 1870-1920, Berlín, Wissenschaften, 1964.

Seminario de Historia Moderna de México, Estadísticas económicas del Porfiriato: Comercio exterior de México, 1877-1911, México, El Colegio de México, 1960.

Seminario de Historia Moderna de México, Estadísticas económicas del Porfiriato: Fuerza de trabajo y actividad económica por sectores, 1877-1911, México, El Colegio de México, 1964. 


\section{ANEXO}

Los siguientes cuadros sintetizan información procedente del corpus que consta de 179 textos (sobre los criterios seguidos para su conformación, véase la nota núm. 7).

\section{Cuadro 1}

CARACTERÍSTICAS GENERALES DEL CORPUS POR TIPO

DE PUBLICACIÓN

\begin{tabular}{lcc}
\hline Tipo de publicación & $\begin{array}{c}\text { Núm. de } \\
\text { publicaciones }\end{array}$ & Porcentaje \\
\hline Artículos & 107 & $60 \%$ \\
Reseñas/Exámenes/Crítica de libros & 68 & $38 \%$ \\
Respuestas & 1 & $.5 \%$ \\
Obituarios & 1 & $.5 \%$ \\
Testimonios & 2 & $1 \%$ \\
Total & 179 & $100 \%$ \\
\hline
\end{tabular}




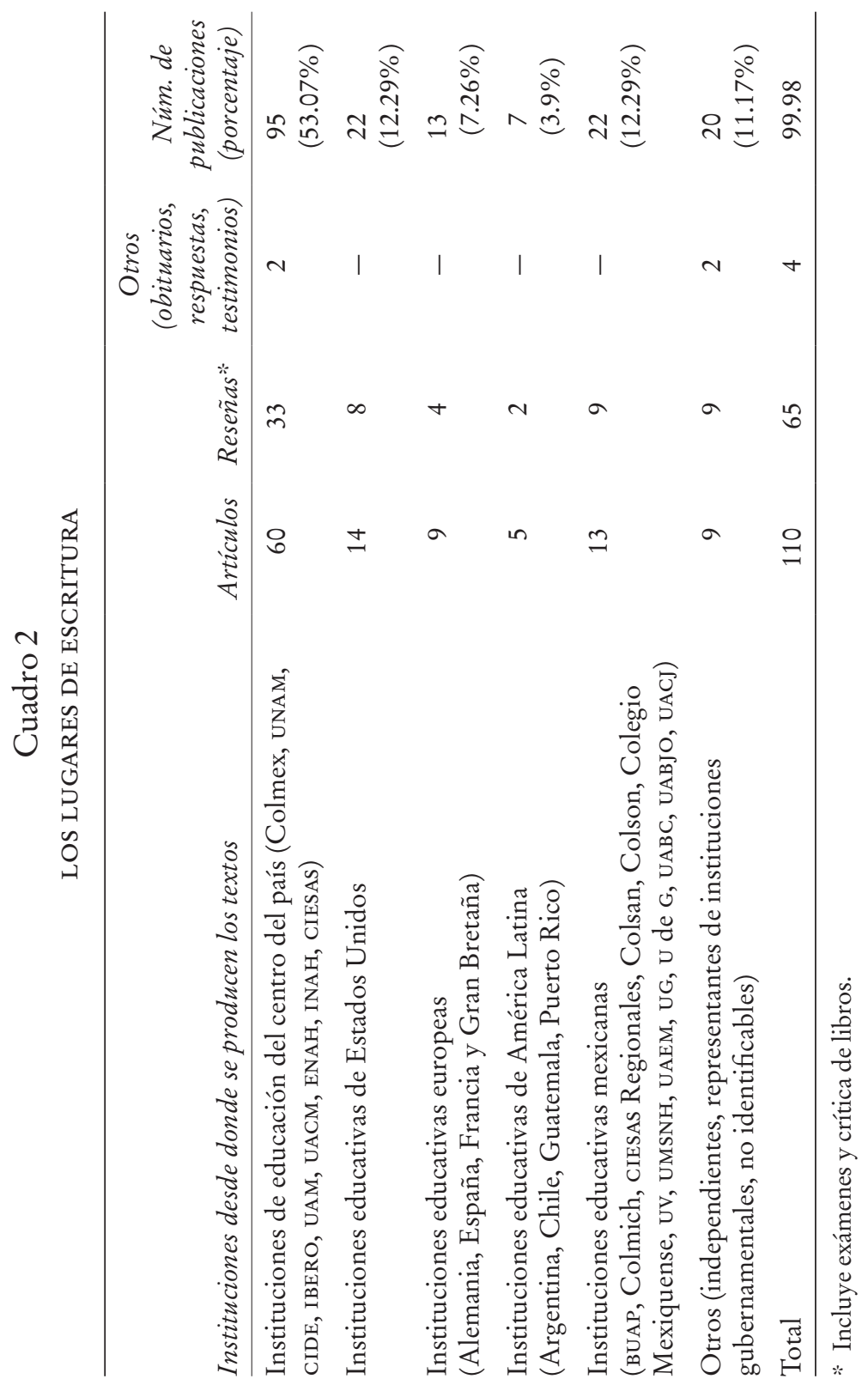


Cuadro 3

ENFOQUES MÁS RECURRENTES*

\begin{tabular}{|c|c|c|c|c|}
\hline Enfoque & $\begin{array}{l}\text { Núm. de } \\
\text { publica- } \\
\text { ciones }\end{array}$ & Artículos & Reseñas & $\begin{array}{c}\text { Otro } \\
\text { (respuestas, } \\
\text { testimonios) }\end{array}$ \\
\hline Historia agraria & 14 & 9 & 5 & \\
\hline Historia cultural & 14 & 9 & 4 & 1 \\
\hline Historia política & 39 & 14 & 23 & 2 \\
\hline Historia social & 27 & 17 & 10 & \\
\hline Historia social y política & 7 & 5 & 2 & \\
\hline $\begin{array}{l}\text { Relaciones internacionales/ } \\
\text { migración }\end{array}$ & 15 & 12 & 3 & \\
\hline Historia económica & 15 & 10 & 5 & \\
\hline Religión y política & 11 & 7 & 4 & \\
\hline Historia militar & 3 & 2 & 1 & \\
\hline Historia urbana & 2 & 1 & 1 & \\
\hline Historia regional/local & 5 & 3 & 2 & \\
\hline Historia de la educación & 4 & 4 & & \\
\hline $\begin{array}{l}\text { Otras } \\
\text { (ambiental, arte, ciencia, } \\
\text { patrimonio cultural, movi- } \\
\text { mientos sociales, vida coti- } \\
\text { diana, balance) }\end{array}$ & 22 & 14 & 8 & \\
\hline Total & 178 & 107 & 68 & 3 \\
\hline
\end{tabular}

* Esta clasificación se ofrece a título indicativo. La asignación del enfoque de los textos se realizó tomando en consideración el título, palabras clave, resumen y la revisión de contenido. En muchos casos, los trabajos pueden corresponder a varios de los enfoques propuestos. No se considera el obituario.

Incluye exámenes y crítica de libros. 
Cuadro 4

ENFOQUES PREDOMINANTES POR DÉCADA

\begin{tabular}{cc}
\hline Década & Enfoques predominantes \\
\hline $1951-1960$ & Historia política \\
& Historia social \\
1961-1970 & Historia política \\
& Relaciones internacionales \\
$1971-1980$ & Historia política \\
& Historia social \\
& Historia económica \\
$1981-1990$ & Historia social \\
& Historia económica \\
& Historia agraria \\
& Relaciones internacionales \\
$1991-2000$ & Historia cultural \\
& Historia económica \\
& Historia social \\
$2001-2010$ & Historia social \\
& Historia política \\
& Historia agraria \\
& Historia económica \\
& Historia cultural \\
& Historia política \\
& Relaciones internacionales \\
& Historia social \\
\hline
\end{tabular}




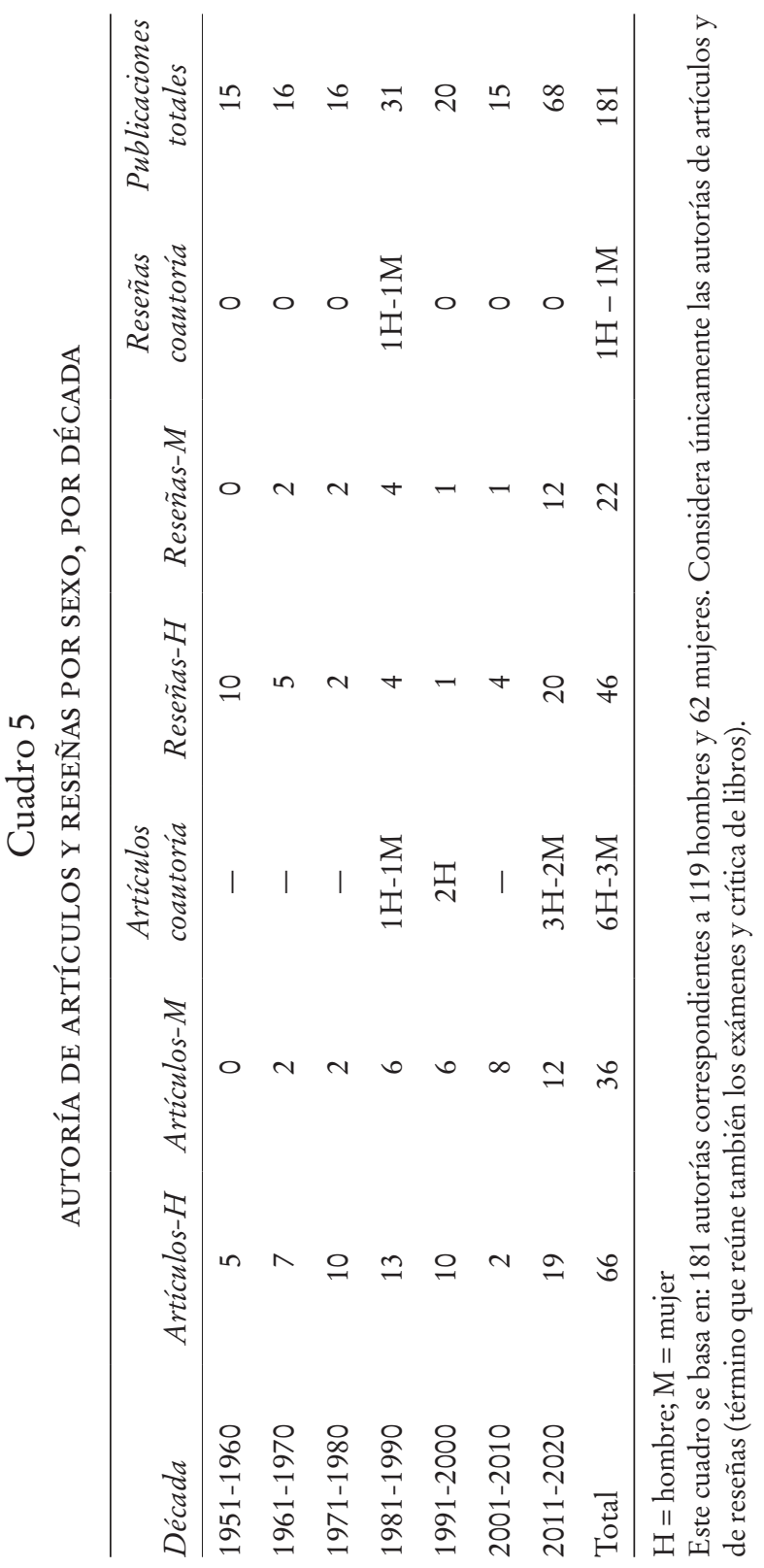

